\title{
O MENINO ATRASADO: CECÍLIA MEIRELES E AS CONTRIBUIÇÕES PARA O TEATRO INFANTIL
}

\author{
O MENINO ATRASADO: CECÍLIA MEIRELES AND \\ CONTRIBUTIONS TO THE CHILDREN'S THEATER
}

Karla Renata Mendes*

\begin{abstract}
Resumo: Cecília Meireles é reconhecida por sua obra poética, sendo destacada como um dos principais nomes da poesia brasileira. Todavia, a autora possui também uma importante produção literária para crianças, abrangendo livros, em sua maioria, ainda pouco conhecidos e divulgados. Deter-se sobre essa parcela de sua obra é avaliar as contribuições da escritora para a formação dos jovens leitores, público esse que sempre fez parte de seu horizonte literário. Assim, espera-se observar sua escrita para o teatro infantil detendo-se sobre o texto $O$ menino atrasado. Trata-se de um auto de natal e constitui-se como única peça teatral infantil composta por Cecília. De difícil acesso, principalmente por ter tido uma única edição, em 1966, o livro traz à tona um gênero pouco cultivado pela escritora e, conforme se anunciava na nota da edição, a peça foi representada desde 1946 "em vários colégios brasileiros", configurando-se, assim, como um tipo de texto aberto a possibilidades de análise e divulgação.
\end{abstract}

Palavras-chave: Cecília Meireles. O menino atrasado. Teatro infantil.

\begin{abstract}
Cecilia Meireles is recognized for her poetic work, being highlighted as one of the main names in Brazilian poetry. However, the author also has an important literary production for children, covering books, most of them still little known and disseminated. To dwell on this part of her work is to evaluate the writer's contributions to the education of young readers, a public that has always been part of her literary horizon. Thus, it is expected to observe her writing for the children's theater dwelling on the text $O$ menino atrasado. This is a Christmas theater and is the only children's theatrical play composed by Cecilia Meireles. Difficult to find, mainly because it had a single edition in 1966, the book brings to light a genre little cultivated by the writer and, as announced in the note of the edition, the play was performed since 1946 "in several Brazilian schools", thus constituting as a type of text open to possibilities of analysis and dissemination.
\end{abstract}

Keywords: Cecilia Meireles. O menino atrasado. Children's theater.

A evocação primeira do nome de Cecília Meireles nos remete de imediato à poesia, vertente literária que a consagrou como uma das mais importantes referências da moderna Literatura Brasileira do século XX. Todavia, além de poeta, ela atuou também em outras frentes, desenvolvendo atividades ligadas ao jornalismo, ao folclore e à educação. Na década de 30, por exemplo, no jornal carioca Diário de Notícias, comandou a "Página da Educação", deixando clara sua oposição ao sistema educacional vigente, expondo sua verve de educadora, que não aceitava imposições do governo como a obrigatoriedade do ensino religioso. Defendendo a teoria pedagógica da Escola Nova, abordando não somente questões educacionais, mas temas como a arte, a ética, o papel das mulheres na sociedade, Cecília Meireles transformou a "Página" num espaço de debate político e ideológico. Ainda como reflexo de sua atuação no magistério e da preocupação com temas ligados à infância, Cecília fundou, em 1934, a primeira biblioteca infantil do Rio de Janeiro e do Brasil, no Pavilhão Mourisco, que se manteve em funcionamento durante quatro anos. Preocupada com a formação educacional de crianças e jovens, a autora debateu questões sobre o tema e atuou de forma muita prática

\footnotetext{
* Doutora em Letras pela Universidade Federal do Paraná, com período de bolsa sanduíche na Universidade de Lisboa. Atualmente, é docente da área de Literatura no curso de Letras da Universidade Federal de Alagoas, Campus Arapiraca. E-mail: krmendes@yahoo.com.br
} 
ao incentivar, por exemplo, a criação dessa biblioteca, fomentando o acesso à leitura e à cultura, de forma geral.

Tal preocupação e mergulho no universo infantil e juvenil também se refletiu ao longo de suas criações literárias destinadas a esse público. Além das obras, propriamente ditas, Cecília lançou, em 1951, Problemas da literatura infantil, uma reunião de três conferências em que se propunha a discutir aspectos desse tipo de produção literária, investigando suas origens e propondo reflexões sobre a interação entre a criança e o livro. Concedendo lugar de destaque ao leitor a quem as obras se destinavam, a autora afirmava, por exemplo, que a literatura infantil deveria ser classificada como aquilo que era lido pelas crianças com "utilidade e prazer", parecendo à autora, mais coerente julgar o livro infantil após submetê-lo ao "uso da criança, que, afinal, sendo a pessoa mais diretamente interessada por essa leitura, manifesta(ria) pela sua preferência, se ela satisfaz ou não" (MEIRELES, 2016, p. 27). Considerando a criança, o leitor, como parte fundamental no processo de concretização da leitura, Cecília permitia-lhe que tivesse voz e manifestasse suas preferências, defendendo a ideia de que os livros infantis fossem, antes de mais nada, uma leitura prazerosa.

Reflexos de sua preocupação com a qualidade do que se oferecia às crianças são suas próprias obras. Buscando levar a esse público textos que representassem o mundo infantil em suas diferentes perspectivas, Cecília não menosprezou o aspecto estético e a construção literária que tornariam mais fácil a fruição dos textos e colaborariam para que a leitura fosse mais agradável. Ainda assim, a obra infantil de Cecília, tão frequente em livros didáticos e manuais escolares, acaba ficando restrita, na maior parte dos casos, a poemas, advindos principalmente de $\mathrm{Ou}$ isto ou aquilo, escrito em 1964. Por outro lado, seus livros em prosa, por exemplo, permanecem quase que desconhecidos do público. Esse é o caso da obra $O$ menino atrasado (escrito em 1946, mas editado em livro apenas em 1966), que se caracteriza como um Auto de Natal e constitui-se como única peça teatral infantil publicada por Cecília. Também de difícil acesso, principalmente por ter tido uma única edição, o livro traz à tona um gênero pouco cultivado pela escritora.

Conforme se anunciava na nota da edição, a publicação da obra acontecia em 1966, em meio às festividades de um "quarto de século da existência", no Brasil, da editora Livros de Portugal, S.A e advinha do desejo de "“associar às bodas de prata" da editora, "o nome de Cecília Meireles - a inesquecível Poeta e gentilíssima Senhora que, desde o primeiro dia, nos distinguiu e acompanhou com a sua permanente dedicação e afectuosa amizade." (In: MEIRELES, 1966, p. 8). Ainda segundo a nota, o teatro fora "escrito em 1946, e representado desde então, em vários colégios brasileiros, com música de Luis Cosme" e somente àquela altura era "impresso em letra de forma". Como a autora falecera em 1964, a nota encerra-se validando a publicação para "os inúmeros admiradores de Cecília Meireles" e agradecendo aos familiares por colaborarem naquele projeto de edição.

Talvez por se tratar de um texto quase desconhecido perante outras obras cecilianas de renome ou por entraves burocráticos envolvendo a reedição de livros da autora, O menino atrasado foi publicado apenas nessa versão de 1966. Tal fato corrobora a ideia de que uma espécie de obscurecimento parece gravitar em torno do teatro ceciliano, uma vez que outras peças de sua autoria (Nau Catrineta, Jogo de sombras, O Jardim e Ás de Ouros) permanecem sem edição em livro até hoje, sendo essas últimas, por exemplo, apenas encontradas em arquivos como o da Fundação Casa de Rui de Barbosa. Além disso, Cecília afirmou em entrevista a Paulo Mendes Campos, no ano de 1947, que estava terminando outras duas peças das quais não se tem nenhum registro, podendo apenas constar nos arquivos da família que permanecem inacessíveis 
à pesquisa. (SOUZA, 2006, p. 19). Assim, uma importante parcela da obra ceciliana em prosa ainda se mantém desconhecida, privando o público de ter contato com o gênero dramático ao qual também se dedicou a autora.

Se o acesso às peças de Cecília são difíceis, encontrar material crítico acerca deles também é tarefa árdua. No caso do teatro infantil, a menção é inexistente em livros teórico-críticos que contemplam a literatura para crianças. Em obras como a de Nelly Novaes Coelho, Literatura infantil: teoria, análise, didática, Cecília Meireles é mencionada apenas como a autora de $\mathrm{Ou}$ isto ou aquilo, em que a poeta "ilumina (para crianças ou adultos) novas maneiras de ver as coisas mais simples do cotidiano (...) ou descobre novas relações entre os seres e as coisas." (COELHO, 2000, p. 244). Já em Literatura infantil: teoria e prática, de Maria Antonieta Antunes Cunha, todo um capítulo dedicado ao teatro para crianças aborda uma grande variedade de autores (Maria Clara Machado, Lygia Bojunga, Lúcia Benedetti), porém nenhum apontamento sobre o teatro ceciliano. Mesmo em artigos que pretendem traçar um panorama da produção infantil específica de Cecília, $O$ menino atrasado não aparece. Tome-se como exemplo o texto "Cecília Meireles, autora de livros voltados aos pequenos leitores", de Norma Goldstein. Embora trace um relevante panorama diacrônico das obras infantis de Cecília Meireles, afirmando de saída que "a produção de Cecília Meireles para crianças abrange várias obras, a maioria delas pouco conhecida e divulgada" (GOLDSTEIN, 2010, p. 47, grifo nosso), o teatro infantil não é mencionado entre os livros da autora. Portanto, nota-se uma carência de reflexões críticas e referencial teórico sobre o teatro e o lugar que ocupa no contexto da produção ceciliana.

Nesse sentido, provém da própria Cecília Meireles algumas ideias sobre sua escrita dramática. De fato, na já mencionada entrevista a Paulo Mendes Campos, publicada no jornal Diário Carioca, em 16 de novembro de 1947, Cecília abordou de maneira mais pontual o contexto de sua produção teatral. Afirmava ela, por exemplo, que seu interesse pelo teatro vinha de muito longe, mais de suas leituras do que dos espetáculos vistos devido à certa carência de qualidade das montagens assistidas. (MEIRELES, 1947, Diário Carioca, s/p). Ao que tudo indica, o envolvimento da autora com a escrita de teatro se deu, primeiro, através das traduções de Ibsen e Lorca, na década de 40, destinadas à encenação por companhias cariocas. Nessa mesma altura e por encomenda, como relata, teria aparecido sua peça infantil: "Correspondi (...) ao convite com que me honrou D. Helena Antipoff, no ano passado, para realizar na Sociedade Pestalozzi um curso de repertório para Teatro de Bonecos, e para o seu teatrinho escrevi o auto de Natal intitulado 'O menino atrasado"'. (MEIRELES, 1947, Diário Carioca, s/p). Teria sido a partir do convite da diretora da Sociedade Pestalozzi e do curso a ser ministrado pela poeta, aos alunos da instituição, que Cecília teria começado a dedicar-se à escrita teatral. Daí a importância de seu pequeno auto infantil como marco inicial de seu percurso pelo gênero. Segundo a pesquisadora Ida Souza, essa peça escrita por Cecília recebeu

cuidadoso tratamento, com músicas ao vivo, compostas e tocadas nas apresentações por Luis Cosme, um compositor gaúcho amigo de Cecília. Os cenários foram elaborados pelas próprias alunas. Essas pequenas "peças" para crianças, com bonecos manipulados pelas "atrizes bonequeiras" formaram todo o repertório inicial de Cecília Meireles. D. Zoé Chagas Freitas, que, depois, se tornou esposa de um dos governadores da Guanabara, era, na ocasião, uma jovem estudante de Direito, interessada pelo trabalho educacional de Cecília Meireles. Como uma das "atrizes"-aprendizes, Zoé lembra-se de ter manipulado alguns dos bonecos. (...) A futura educadora (D.Zoé acabou deixando 
o Direito e, por admiração ao trabalho de Cecília, passou a se dedicar à educação) se recorda da imagem de Cecília, gravada por seus alunos e pelas futuras atrizes que compunham o grupo de "bonequeiras": "Cecília Meireles às vezes fugia de sua austeridade de professora e tornava-se muito divertida. Tinha muito senso de humor e fazia comentários agudíssimos para D. Helena". (SOUZA, 2006, p.14)

É assinalável o apagamento dessa incursão ceciliana pelo gênero dramático e sua atuação em projetos na área - com esse desenvolvido junto à Sociedade Pestalozzi - os quais seriam a motivação para a escrita de obras como $O$ menino atrasado. Foi a partir dessa oficina de teatro de bonecos, por exemplo, que a aproximação da autora ao teatro se efetivou com mais ênfase.

De fato, parece pouco justificável que a criação dramática de Cecília Meireles permaneça sem visibilidade, já que a autora sempre manifestou proximidade ao gênero, traduzindo peças e refletindo sobre sua produção. Em relação às conexões do teatro ao mundo da infância, Cecília já deixava clara, ao longo de algumas crônicas, a ideia de que o teatro e a educação mantinham uma relação intrínseca, sendo esse um gênero extremamente apropriado às crianças devido ao seu aspecto lúdico e formador, porém, de difícil execução e de grande responsabilidade. Em crônica escrita em 1932, Cecília lamentava que no Brasil houvesse uma carência de teatro, como um todo, e em especial de peças destinadas a crianças, destacando também sua visão do teatro como uma ferramenta de educação, o que tornava o desafio ainda maior:

Teatro para crianças num país em que ainda não temos, verdadeiramente, um teatro para adultos, é empresa difícil e de enormes responsabilidades. Já seria bastante termos espetáculos que visassem distrair a infância e a juventude sem as deseducar. Poderíamos ter, também, um teatro que instruísse. Mais complicado, talvez, pelo risco sempre iminente de enfastiar. (MEIRELES, 2017, p. 78)

Não perdendo de vista sua atuação como educadora e encarando a literatura para crianças e jovens como um instrumento de formação, e não apenas de entretenimento, Cecília Meireles percebe o teatro como uma ferramenta de instrução mais ativa. Para ela, o teatro infantil operaria em duas frentes gerando um encantamento e um momento de recreação pelo espetáculo performático em si; e propiciando um momento de aprendizagem e reflexão se o texto fosse concebido com seriedade e comprometimento. Todavia, como ela afirma, ao se pretender que os espetáculos não só divertissem, mas também instruíssem, havia o risco de torná-lo enfadonho ou pedagógico demais.

Tal preocupação em tornar o texto literário para crianças fonte de prazer e reflexão sobre o mundo permeou toda a criação ceciliana voltada a esse público. Embora frisasse a importância do caráter formativo desse tipo de livro, Cecília nunca perdeu de vista que, antes de mais nada, eles precisavam atender a um caráter estético, poético e literário, priorizando o valor enquanto texto e obra de arte e não somente enquanto propagador de valores e ensinamentos. Refutando a ideia de que escrever para crianças seria mais fácil por se tratar de um público menos exigente, Cecília sempre salientou que a literatura destinada aos pequenos deveria cercar-se ainda mais de cuidados e atenção por parte do autor. Assim, a poeta sempre acentuou a complexidade envolvida no ato de compor para infância, como se atesta nessa passagem de Problemas da literatura infantil:

Muita gente pensa que escrever para a infância é das coisas mais 
fáceis. Que esses leitores são pouco exigentes; que não é preciso ter "estilo" (todo o mundo tem o direito de pensar coisas absurdas) para escrever qualquer página que os satisfaça. E - o que é maior enormidade - que qualquer assuntozinho à toa se presta para um livro desses, destinado a quem não tem muitas preocupações fora do círculo da família e da escola. (...) Simplicidade não quer dizer banalidade. Pode-se fazer um livro extremamente simples - porque há que atender aos recursos limitados de vocabulário, de primeira idade - mas repleto, ao mesmo tempo, desse aroma de poesia que devia ser alimento contínuo da infância. E também se pode fazer um livro maravilhoso - mas sem monstruosidade, condições que muita gente supõe afins. (MEIRELES, 2016, p. 97-98).

A visão de que não se deveria confundir simplicidade com banalidade, no momento de escrever para a infância, permeou diversos escritos de Cecília sobre o gênero. Essa preocupação não se ateve, obviamente, apenas à teorização sobre o tema, mas foi colocada em prática ao longo das criações da autora para os pequenos leitores, havendo nos textos, constantemente, essa preocupação em evocar o "aroma de poesia que devia ser alimento contínuo da infância”. Assim, se na poesia infantil, Cecília dava vazão a aspectos que já lhe eram caros (musicalidade, lirismo, ritmo), ao longo de suas obras em prosa destinadas a crianças, tais pontos também não eram esquecidos, havendo ali também espaço, em muitos momentos, para uma linguagem mais poética, metafórica, lírica e simbólica. Essa procura por uma espécie de prosa poética é um fenômeno observável também nas produções dramáticas cecilianas. Como ela mesma atesta, na já referida entrevista a Paulo Mendes Campos, a escrita de peças fazia parte do desejo de "criar um pequeno teatro "poético", conforme explica:

Finalmente, convencida de que já se poderiam fazer certas experiências de teatro, no Brasil, graças ao crescente entusiasmo de empresas, atores, autores e espectadores, animei-me a essa prova tão difícil para um autor: tentar outro gênero literário. Notei então que se firmava em mim um grande interesse pela parte "literária" das peças. (...) Fixei, porém, o caráter "poético", porque o senti na minha própria experiência. E porque esta é a minha linguagem literária. A tal ponto que, mesmo escrevendo em prosa, mesmo conversando, por vezes me sinto essa "claridade" que têm os que "pensam em prosa". (MEIRELES, 1947, Diário Carioca, s/p).

A definição encontrada por Cecília - teatro poético - para tentar captar a essência de seus textos teatrais parece perfeitamente adequada. Como ela mesma afirma, a linguagem poética era sua forma mais genuína de expressão e criação literária. Assim, ao assimilar toda uma tradição de diálogo entre poesia e drama e conferir aos seus textos esse tom poético, buscava-se, de certa maneira, uma harmonização a todo o seu projeto literário. Além disso, para a autora, essa procura pela poeticidade tratava-se de um investimento na "parte literária das peças", ou seja, além de adaptar-se às regras convencionais de escrita do gênero, a qualidade literária e artística também estavam no centro de seu processo criador.

Com $O$ menino atrasado não foi diferente. Embora seu enredo, em tese, seja simples - por se tratar de um auto de natal, celebra o nascimento do Menino Jesus Cecília singulariza a narrativa, atribuindo-lhe uma nova roupagem. Mantendo o desejo de compor um "teatro poético", a autora narra o episódio central utilizando-se de rimas, 
ritmo e versos ao longo das falas dos personagens. Além disso, outro elemento peculiar é a inserção de aspectos folclóricos ao longo da narrativa e que procuram celebrar a multiculturalidade brasileira, tornando a visão clássica do nascimento de Jesus uma história variada e diferente da tradicional.

A obra conta com uma Introdução, divide-se em dois atos e possui um epílogo. Na curta Introdução, somos apresentados ao cenário ("clarão da madrugada") e a três personagens ("Galo", "Boi" e "Ovelha") que são, de fato, os primeiros a anunciarem o nascimento do menino. Numa ação orquestrada, o galo, "no centro", "bate as asas e canta: Jesus nasceu! Jesus nasceu!"; enquanto isso o boi, "à esquerda", questiona-se "onde?" e, à direita", a ovelha reverbera: "Em Belém! Em Belém! Em Belém". (MEIRELES, 1966, p. 8). Correspondendo ao que seriam quase os sons emitidos por esses animais, a natureza se adianta aos homens celebrando, de antemão, a boa nova. Tratando-se de uma peça destinada a crianças, esse apelo inicial - colocando os animais em cena - poderia ser um mas s homens e j esses animais, a natureza $\mathrm{r}$ iza e de Portugal. 131131131131131131131131131131131131131131131131131131131131131131étodo para atrair a atenção e também conceder uma leveza (ou até humor) ao texto.

$\mathrm{Na}$ sequência, a primeira cena do primeiro ato retrata a celebração do anúncio "oficial" do nascimento de Jesus, feito por "um coro de Anjos como os de Aleijadinho" às "Pastorinhas e aos Pastores reclinados debaixo de uma árvore, cheia de flores e passarinhos". (MEIRELES, 1966, p. 9) Seguindo a história bíblica, anjos anunciam a chegada do Salvador aos pastores que cuidavam de seus rebanhos. Todavia, Cecília aqui dá novos tons à história porque insere "Pastoras" a quem os anjos se dirigem primeiramente e de maneira efusiva:

\author{
Anjos: \\ Pastoras, belas Pastoras \\ que na relva estais deitadas, \\ descansais e não sabeis \\ que a luz do céu é chegada? \\ (Voando com animação de baile) \\ Todo o céu e a terra \\ vos cantam louvor, \\ ó Menino Deus, \\ nosso Redentor! \\ (MEIRELES, 1966, p. 9)
}

É interessante notar que Cecília evoca os elementos do universo poético organizando o discurso em quadras (uma forma poética popular, simples e de fácil memorização) e seguindo uma cadência rítmica alcançada através das rimas intercaladas. Além disso, vê-se de imediato imagens carregadas de subjetividade e lirismo como a definição do menino de que esse seria "a luz que do céu é chegada." $O$ primeiro personagem humano a ter voz será justamente a " 1 a . Pastorinha" que retoma os fatos acontecidos na introdução para convocar seus companheiros pastores à celebração:

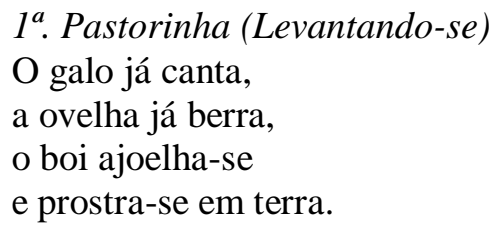




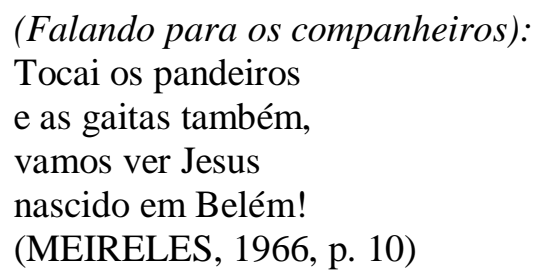

Esse convite feito pela personagem acaba despertando os outros pastores que, após confirmarem a boa nova, colocam-se em celebração, conforme descreve a orientação da autora: "enquanto dançam e cantam, começam a sair da árvore passarinhos, que dão voltas pelo ar." (MEIRELES, 1966, p. 10). Juntar-se-á aos pastores e pássaros, logo na sequência, também uma borboleta. Observa-se que as festividades envolvem todos os seres e os colocam num espírito de comunhão em que todos se sentem unidos e felizes.

Assim, os pastores e a Borboleta iniciam sua caminhada até Belém quando surge em cena a figura curiosa de "três ciganinhas". Assumindo a função de uma espécie de "coro", elas anunciam o que está se passando em cena: "Lá vão as pastoras, / lá vão os pastores / com cestas de frutas / e cestas de flores". (MEIRELES, 1966, p. 12) Além de explicar que eles seguem o caminho até Belém, levam presentes e "vão ver o menino", as ciganas decidem ir junto. As três, seguindo os preceitos de seu ofício, afirmam já saber qual seria o destino da criança e afirmam ainda que o Menino "mandará na Morte". Embora visando a um público infantil, o teatro conta com momentos que vão além do mero entretenimento ou da narrativa fácil. A ideia de uma menino que manda na morte é carregada de significado e coloca em perspectiva todo o poder divino que emana daquela simples criança.

É na formação desse cortejo, que segue para visitar Jesus, que a autora decide inserir uma ampla variedade de personagens que traduzem um pouco da pluralidade brasileira. Todos seguem obstinados pelo desejo de reverenciar o recém-nascido, levando-lhes presentes que simbolizam a essência de cada um. Dessa maneira, surgem "duas pretinhas de roça, com uma colcha e um cobertor, afirmando: "o presente é de pobreza, mas o sentido é de amor"; "três Roceiros com cestinhos nos braços", levando alimentos como queijo, cajá, melado, mel e rapadura" e, finalmente, baianas que "cantam em seu pregão":

Olha o pé de moleque, a cocada preta e branca e côr di rosa!

(...)

Levamos cocadas,

Levamos cuscuz

e bolo de milho

pra dar a Jesus.

(MEIRELES, 1966, p. 13-14).

É interessante e inusitado que, no teatro ceciliano, o Menino Jesus estivesse prestes a receber prendas como cajá ou cuscuz. Há um evidente desejo de regionalizar a cena, inserindo nela personagens e elementos tipicamente brasileiros. A tentativa de caracterização desse regionalismo se traduz na linguagem como no pregão da baiana que canta "cor $d i$ rosa" e também serão enfocados quando aparece em cena um "violeiro do Norte que canta para a sua companheira" da seguinte forma: "Menina, si queres vamos, / não te põe a maginá! /quem magina cria medo / quem tem mêdo não vai lá!" (MEIRELES, 1966, p. 15) Para fixar o convite entoado pelo violeiro o texto recorre ao 
registro da oralidade, de uma variedade linguística que reforça essa valorização do regional.

Tal resgate e louvor do folclore nacional ficam ainda mais explícitos quando Cecília coloca em perspectiva um grupo de personagens formado por: "Costureira, Cozinheira, Gaúcho e Vaqueiro do Norte". Como se observa, tais personagens constituem-se quase que como "personagens-tipo", sendo identificados por suas funções e não recebendo um tratamento individual. Ao introduzir o vaqueiro em cena, a autora distingue-o como o mestre de cerimônias da representação do "Boi Tungão - Côco de Ganzá", uma dança de roda acompanhada de música e presente em festas populares do Norte e Nordeste brasileiros:

Solo:

Ó li, li, liô!

Côro:

Boi Tungão!

Solo:

Boi do maiorá!

Côro:

Boi Tungão!

Solo:

Eu tava em casa, tava danado no quarto, tava bebo de aguardente quand' ouvi chamá.

Era uma nêga, Chamada Quitera;

Essa negra falou sério:

Chico Antônio vá!

Todos repetem em côro:

Chico Antônio, vá!

(MEIRELES, 1966, p. 16)

Chico Antônio, a quem o texto faz referência, tratava-se realmente de uma figura representativa do folclore brasileiro. Morador do Rio Grande do Norte, ele se popularizou graças a Mário de Andrade. Como se sabe, uma das bandeiras dos modernistas era justamente uma valorização da cultura brasileira. Empenhado nesse projeto, o autor de Macunaíma percorreu várias regiões do Brasil, na década de 20, e conheceu figuras variadas como Chico Antônio, de quem recolheu por volta de cinquenta côcos. Os encontros entre o autor modernista e o cantador ficaram registrados ao longo de algumas de suas crônicas da obra $O$ turista aprendiz. Como afirmava Mário de Andrade, havia uma espécie de êxtase que tomava conta do cantador ao entoar seus côcos:

Para tirar o "Boi Tungão", Chico Antonio geralmente se ajoelha. Parece que ele adivinhou o valor artístico e social sublimes dessa melodia que ele mesmo inventou e já está espalhada por toda esta zona de engenhos. Então se ajoelha para cantá-la (...) Estou divinizado 
por umas das comoções mais formidáveis da minha vida. (ANDRADE, 2015, p. 314-315)

Pela proximidade entre Cecília e Mário, é provável que a autora tenha tomado conhecimento da figura de Chico Antônio graças aos registros do escritor, mas sua ligação com o folclore sempre foi latente. Além de pensar nas relações dessa área com a educação, Cecília procurou uma atuação mais prática sendo membro de comissões sobre o tema e ajudando na organização do I Congresso Nacional do Folclore, no Rio Grande do Sul, nos anos 40. Assim, a inserção de um côco em um auto de Natal infantil revela justamente seu desejo de propiciar aos pequenos leitores um contato com a cultura popular brasileira, tão rica e variada. Em Problemas da Literatura Infantil, a autora já destacava a importância de se ter um conhecimento sobre o folclore que equivaleria a um conhecimento sobre a nossa própria essência:

O folclore faz parte da cultura geral. Não se pode admitir, mesmo no homem comum, o desconhecimento do folclore. É uma espécie de humanismo pré-escolar. (...) Uma criatura que não sabe canções de roda, adivinhações, brinquedos, histórias, parlendas, não teve infância, está mutilada, não pode ser feliz, não pode educar seus filhos, não entende nada de si nem de seus conterrâneos, nem do homem, em lugar nenhum do mundo (MEIRELES, 1979, p. 72).

Fica explícito, na citação, o valor que a autora concede ao folclore e a defesa da necessidade que as crianças tivessem contato com manifestações da cultura popular, correndo o risco, se não o fizessem de não entenderem "nada de si". Talvez esse argumento ajude a entender a inserção das passagens do "Boi Tungão" na história do Menino atrasado. No caso do côco de Chico Antônio, a reprodução da letra da canção entoada pelo cantador não é simplesmente colocada a esmo no texto apenas para que houvesse a inserção de um trecho folclórico, mas se adequa ao texto e à descrição dos fatos, uma vez que a música é uma espécie de incentivo para que o vaqueiro também se junte àqueles que vão ver o menino (“Chico Antônio, vá!").

Cumprindo a mesma função, Cecília também coloca em cena um "Gaúcho" que afirma: "Eu levo para o Menino / filho de Deus tão formoso, / um boizinho de verdade, / primo, irmão do boi Barroso. / Eh, meu boi Barroso!” (MEIRELES, 1966, p. 16). De fato, a canção do Boi Barroso é uma das mais famosas peças do folclore gaúcho, figurando ao lado de canções emblemáticas como "Prenda minha". Como afirmado anteriormente, a organização de um Congresso no Rio Grande do Sul provavelmente fez com que a autora se aproximasse muito da cultura gaúcha. Estabelecendo diálogos entre canções portuguesas e gaúchas, ela já havia defendido, em crônicas, a ideia de que o folclore gaúcho incorporou à sua tradição versos da música lusitana, o que teria resultado na composição "Prenda minha" ou, ainda demonstrado que a adaptação de músicas portuguesas teriam gerado aqui canções muito populares, como por exemplo, o "Pezinho" (MEIRELES, 1999, p. 89). Nesse contexto de destaque da cultura do Sul, a autora deixa a recomendação de que houvesse, na peça, a inserção da música: "(Ouve-se um pouco da música tradicional do Boi Barroso: Adeus menina, que eu vou-me embora, etc..., enquanto o gaúcho desaparece). (MEIRELES, 1966, p. 17).

É curioso notar que em determinada altura Cecília busca equilibrar a presença desses personagens, à primeira vista, inusitados em um Auto de Natal com aqueles já tradicionais. Assim surgem os Reis Magos em posse de seus presentes já conhecidos (ouro, incenso e mirra), e com eles finda-se o primeiro ato e inicia-se o segundo, também obedecendo à história "oficial" e tendo como espaço um "presépio, à maneira 
clássica" e anjos que trazem "a fita com a inscrição: "Glória a Deus nas alturas e paz na terra aos homens de boa vontade"”. (MEIRELES, 1966, p. 21) Embora a cena pareça transcorrer dentro do esperado, com a oferta dos presentes ao Menino, logo o episódio ganha novamente um personagem peculiar: um poeta que segura um copo de vinho e oferecerá um brinde ao recém-nascido nesses termos:

Sô un pueta que falu di hora in hora

qui in quanto as coisa milhora

i as moça mi namora

um, dois i trêis,

vamos todu dá un viva

nu glorioso santo Reis.

Eu vim du sertão

tocanu meu violão,

trazenu sôdade

deixanu paixão

vamos todu dá un viva

nessa rica união

Sô un pueta

falu contenti

lóvu quem tá osenti

i lóvu quem tá presente

um, dois i trêis

vamos tudo dá un viva

nu glorioso santo Reis.

(MEIRELES, 1966, p. 22)

Afirmando que vem do sertão, o poeta/violeiro encarna a figura de um literato popular. Embora "poeta", sua fala-se registra-se com evidente predomínio da oralidade, marcando um discurso que foge da norma padrão. Marcado pelos "desvios" à norma, seu brinde tem grande carga simbólica: é a exaltação da cultura popular reverenciada ao longo de todo o teatro, pois é nesse momento, e graças ao poeta, que os demais personagens interagem em cena num mesmo gesto de celebração coletiva pelo nascimento do Menino. Motivados por sua fala todos, antes vistos isoladamente, se reúnem nessa saudação ao "glorioso santo Reis".

Além de marcar a união dos personagens, a fala do poeta é uma espécie de desfecho para a história daqueles que vinham ver e presentear Jesus. Após o brinde, os demais saem de cena e surge finalmente o "menino atrasado", que dá título ao teatro:

O presépio está no cimo de uma colina. No primeiro plano, deverá haver uma cerca, uma porta e um porteiro. (...) Aparece um menino atrasado, olha para os lados, espia, canta:

O Menino:

Todos já se foram!

Não há mais ninguém!

Dizem que o menino

nasceu em Belém!

Eu não tenho irmão,

não tenho um amigo, 


\begin{abstract}
quero esse menino
para brincar comigo!

Por onde será

que os outros já vão?

$\mathrm{Eu}$ quero o menino

para meu irmão!
\end{abstract}

(MEIRELES, 1966, p. 23)

O menino atrasado, como se percebe, aparece também buscando aquele que "nasceu em Belém”, porém com outra motivação: trata-se de uma criança solitária que, muito mais do que presentear o Menino, quer que ele seja seu irmão e companhia de brincadeiras. Uma vez que não chega a tempo, o menino suplica ao porteiro que o deixe cruzar a porta para chegar até o presépio, todavia ouve dele apenas negativas: "Saia daqui, / volte pra casa. / Quem vai à festa / não se atrasa", "Vá-se embora, vá-se embora,/ não chega em nenhum lugar! / Veio com as mãos abanando! / Que trouxe para lhe dar?" (MEIRELES, 1966, p. 24). Embora tente explicar que veio até ali para brincar com o seu "camarada", que não trouxe nada por ser pequeno mas que vai entreter o amigo com "pião, papagaio, / gude, amarelinha / cantigas e danças", o porteiro não se compadece e o trata cada vez mais com irritação e desprezo:

\author{
O Porteiro: (Zangadíssimo) \\ Vá para casa depressa! \\ Não lhe digo isso outra vez! \\ Então pensa que o Menino \\ é assim como vocês? \\ Este é o Rei da Humanidade, \\ não vai como vocês vão \\ perdendo o tempo nas ruas \\ com papagaio e pião! \\ (MEIRELES, 1966, p. 25)
}

Diante da fala cruel do Porteiro, no encerramento do segundo ato, o menino começa a chorar e acaba adormecendo ao pé do portão.

Já no epílogo, surgem anjos que levam Jesus para fora do presépio causando espanto entre os demais personagens assombrados com sua saída repentina. Nesse momento, o até então Menino, recebe voz e canta agora identificado como Jesus:

Jesus: (Canta)

Quem foi que chamou por mim?

Ouvi, levantei-me e vim.

Quem disse que me quer bem?

Eu lhe quererei também.

Quem quer ser o meu irmão?

Estenda-me a sua mão.

(MEIRELES, 1966, p. 29)

Como se nota, a fala de Jesus ao Menino Atrasado remete muito ao discurso bíblico presente em Evangelhos como o de Lucas e Mateus, quando ele afirmava que 
deixassem as crianças virem até ele porque delas era o Reino dos Céus. É nesse momento que o garoto acorda e reitera o convite à brincadeira, sendo aquele encontro celebrado por todos (com exceção do Porteiro, que se afasta), em coro com os anjos: "Noite feliz, noite ditosa, / noite, pra nós, tão venturosa". (MEIRELES, 1966, p. 30). A acolhida de Jesus ao menino reforça valores como a humildade, bondade e compreensão. Embora o texto frise que todos iam prestar reverência aquele que era considerado um rei, o final destaca sua generosidade e simplicidade ao acolher o menino e retribuir o amor que lhe era oferecido. Por fim, o espetáculo encerra-se com a borboleta que volta à cena apenas para se despedir do público: "Eu venho cumprimentar, / eu venho dizer bom dia! / Adeus, adeus, boa gente, /Deus lhes dê paz e alegria!". (MEIRELES, 1966, p. 30)

Conforme se intentou demonstrar, o teatro infantil de Cecília Meireles corrobora sua preocupação com a infância e com a qualidade do que se produzia em termos de literatura para essa faixa etária. O desejo de fazer chegar às crianças textos que divertissem e também ensinassem, reverberando na formação humana desse público, sempre foi manifestado pela autora. Na crônica "Depois do espetáculo", por exemplo, ela afirmaria: "Um pouco de cor, um pouco de luz, um pouco de movimento, um pouco de som - e esse pequeno mundo $\square$ da infância $\square$ se anima, se entusiasma e se proclama sinceramente feliz. (...) Mas alegrar a criança educando-a, elevando-a, - isso já é outra coisa, diferente, e muito mais difícil." (MEIRELES, p. 48). Comprometida com o desejo de unir, num espetáculo teatral infantil, o lúdico e o aprendizado, Cecília concebeu $O$ menino atrasado como uma peça que proporciona às crianças o contato com a história do nascimento de Jesus, o que para a maioria delas já poderia ser familiar, e, para além disso, estimula uma aproximação com a cultura popular brasileira em suas variadas facetas tais como a comida ou música. Por tudo isso, crê-se que o teatro infantil ceciliano mereça ser resgatado e evidenciado ao lado de outras de suas obras para infância já tão consagradas. Fazendo de seu texto um palco para difusão de aspectos da identidade nacional, a autora cria uma peça em que a história cristã funde-se ao folclore brasileiro e coloca em perspectiva alguns dos tipos que compõem esse rico painel popular e que ajudam também a contar um pouco da nossa narrativa enquanto povo.

\section{Referências}

ANDRADE, Mário de. O turista aprendiz. Brasília: Iphan, 2015.

COELHO, Nelly Novaes. Literatura infantile: teoria, análise, didática. São Paulo: Moderna, 2000.

CUNHA, Maria Antonieta Antunes. Literatura infantil: teoria e prática. São Paulo: Ática, 2006.

GOLDESTEIN, Norma Seltzer. "Cecília Meireles, autora de livros voltados aos pequenos leitores". In Linha D’Água, n. spe, p. 47-57, 2010. Disponível em: http://www.revistas.usp.br/linhadagua/article/view/62339/65143

MEIRELES, Cecília. O menino atrasado. Rio de Janeiro: Livros de Portugal, 1966. . Crônicas de viagem.(vol.2) Rio de Janeiro: Nova Fronteira, 1999. 
Problemas da literatura infantil. São Paulo: Global, 2016.

Crônicas da educação (vol. 4) São Paulo: Global, 2017.

Diário Carioca, ano XX, Entrevista e notas de Paulo Mendes Campos, "Sempre houve crises", 16 de novembro de 1947, ed. 05949. Disponível em: $\square$ http://memoria.bn.br/DocReader/DocReader.aspx?bib=093092_03\&PagFis=30563\&P esq=sempre\%20houve\%20crises $\square$ Acesso em: 15 de maio de 2019.

SOUZA, Ida Vicencia Dias de. "O Teatro Poético de Cecília Meireles" (Tese de Doutorado) Rio de Janeiro: PUC, Departamento de Letras, 2006. Disponível em: $\square$ https://www.maxwell.vrac.puc-rio.br/9055/9055_1.PDF $\square$ Acesso em: 15 de maio de 2019.

Recebido em 20 de julho de 2019

Aceito em 23 de agosto de 2019 